\title{
The New Pattern of Talents Cultivation in Medicine University of China's Western Mountains
}

\author{
Xiaoyan Wang ${ }^{1}$ \\ ${ }^{1}$ Hubei University of Medicine \\ Shiyan, 442000 China \\ e-mail:xywangdk@163.com \\ Jianguo Wang ${ }^{1}$ \\ ${ }^{1}$ Hubei University of Medicine \\ Shiyan, 442000 China \\ e-mail:whywxqwjg@sina.com
}

\author{
Chenxi Wang ${ }^{2}$ \\ ${ }^{2}$ China Women's University \\ Beijing, 100101 China \\ e-mail: 249265769@qq.com \\ Deng Kai ${ }^{1 *}$ \\ ${ }^{1}$ Hubei University of Medicine \\ Shiyan, 442000 China \\ e-mail: dkeanig@163.com \\ * Corresponding Author
}

\begin{abstract}
The shortage of medical services and supplies in China's mountainous area in west has not been resolved today. Though the university of medicine in this area tried to expansion the enrollment scale, the fruit seems an utterly inadequate measure, tiny of the graduates would like to stay behind, suitable to the countryside, take root in the mountains and can fully qualified for the masses, Not to mention grow up to be a qualified health workers. Therefore, we excogitated a suit of new pattern to solve the issue of talents cultivation, Put forward, discussed and demonstrated the most auspicious and optimization innovation design scheme of the talents cultivation mode.
\end{abstract}

Keywords-China; mountainous area in west; medicine; university;education; pattern

\section{INTRODUCTION}

Nowadays, with the development of our society, the demands for talents presents the characters of multilevel, diversification and compound, this determined the diversification of talents cultivation in medicine university. on the other hand, the discrepancy of school's own conditions or the different physical characteristics of educational objects also requires the talent training adopting diversified forms. And the optimization the pattern of talents cultivation was proceed from the height of comprehensively promote quality-oriented education. It is a training mode whose goal is to foster talents development in an all-around way with high quality and innovative, consequently, It becomes the supremacy of talents cultivation. Diversification and optimization supplement each other, diversification is the basis and premise of optimization, and for the other hand, the highest order of diversification is optimization. diversification leads to characteristics while optimizing turns out high quality. The reformation of talents cultivation pattern should realize the goal of optimization on the foundation of diversification. So the talents cultivation pattern essentially a ageneraldesignation of a series teaching organization and processes, which works under the direction of definite educational thought or concepts, composed by the components of Educational Object, targets, contents, methods, approaches and the evaluation criterion of quality assessment, concentrated reflecting the relatively stable of education and teaching patterns .The structural elements mainly include how to set up degree Programmes, educational objectives ,the classification of talents cultivation, Training Scheme contains curriculum system and content of courses, also, it introduced the approach and mechanism for talent training.

\section{THE DIVERSIFICATION AND OPTIMIZATION TALENTS CULTIVATION MODE IN MEDICINE UNIVERSITY OF WESTERN MOUNTAINOUS AREA}

The diversification and optimization talents cultivation mode in medicine university of western mountainous area is determined by the characteristic of Territories. on account of history and natural, the development of economics, culture, educational enterprise in western mountainous area lags behind southeast and flat area for a long time, moreover, The uneven development between territories cause the situation that quite a number of areas still of underserved hitherto in this area, the whole level of Medical Treatment and Public Health are lower. Consequently, in the first place, personnel cultivation objective of higher medical education in western mountainous areas must be able to meet the needs of the medical and health services of this region at the present stage, directly security services for the majority of the people's health. On this basis, This paper is from the point of adapting the requirement of society sustainable economic development, further medical model transformation and the Progress of medical science. And not only that, the talents that we cultured must have conditions and potential of sustainable development whole life long, further more, It requires them to contribute to increase the western mountains medical and health level, or to promote the medical science business develop greatly. According to these requirements, the talents cultivation mode in medicine university of western 
mountainous area should be diversification and optimization. First of all, most of them must Geared to the grass roots and service community, work for the majority of the people's health services, in other words, they can go work for the grassroots, paul smith channel, keeps to stay here when we need, they are in famous precinct with specifications and practical talents, All of them must be possessed of solid professional foundation knowledge, specialized practical skills and noble moral character and profound humanistic spirit. They would like to take the masses of people's health benefits as his life-long commitment, on the other hand, they are also rich in the sense of responsibility and dedication, serve for the western mountainous areas in obscurity. Above all is what we said when it comes to the diversification of talents cultivation. Starting from this foundation, To meet the requirements of culturing talents with high-quality, we training students with good learning ability, thinking ability, innovation capability and promote the scientific spirit, finally when they have the potential for lifelong sustainable development condition, a portion of personnel with high caliber may get somewhere in the field of medical scientific research and medical education, further more, they can grow up to become nucleus to promote the level of Medical Treatment and Public Health in western mountain areas and to promote long-term development of medical education. This is the optimization on the basis of diversification in professional training mode.

\section{THE REFORM AND EXPLORATION OF THE DIVERSIFICATION AND OPTIMIZATION TALENTS CULTIVATION MODE}

\section{A. Establish the professional structure to adapt to the demand of the society}

The professional structure is One of the important factors of the cultivating mode. Our first priority of innovate talents cultivation mode is to establish a appropriate professional structure. Previously, the professional competence structure in medicine institutions are singleness.

Generally only sets up the disciplines according to the foundation and conditions of the school itself, the talents cultivated often can not adapt to actual need to the society, Resulting in the phenomenon of shortage and waste of talents, and failed to take a active role in the education for promotion of social development, thus weakened the function of education. This is obviously not conform to the law of education development.

According to the rules of the internal relation of external relations, that education must adapt with the social development and the need to promote individual development, it must starting from the characteristics of the western mountain area of social and economic development and medical education, The structure of professional medical colleges and universities in the western mountainous area should be a multilevel and multiple dimensions, in an other word, it should fully embody the education philosophy of "Multi channel learning,thick foundation, high quality, emphasis on personality, and Attaches great importance to the innovation".thus the talents can not only adapt to the society of multilevel, multifaceted needs,but also simultaneously pays great attention to their all-round
development.First of all, The personnel training of professional caliber should broaden appropriately, at the early stage,we can recruit students by major class and culture them with abstract, construct the broad and thick basic education platform with a general education objectives and requirements, cultivating students with solid,tight foundation of knowledge and basic skills. Then targeted professional education and set up different professional direction according to the social needs of education. For the Clinical Medicine Science, the elementary stage can be divided as a genera, contemporary, the secondary discipline such as preventive medicine, oral medicine, biological engineering, pharmacy and nursing all or part of foundation courses can also be convergence of clinical medicine specialty at the early stage, Then the professional direction of shunt later.In the next place,based on the diversification of professional discipline, schools should construct one or two key professional on the basis of their foundation and advantage to foster a batch of talents with high quality, strive capacity and potential of creative thinking, drive and promote the development of related disciplines simultaneously, finally create their own characteristics.Such as the professional structure, not only has to meet the social needs of the space, but also have a sustainable development,Change freely with broad, narrow, length and short.

\section{B. Build a Scientific and reasonable curriculum system}

\section{1) Set up a staunch and clement Basic education} platform

The grundstudium of Medical Colleges can be divided into two types: Public elementary courses and professional basic course.

Public elementary courses mainly include ideological and political theory course, elementary course of natural science, foreign language, physical education class, basis of computer engineering and so on, which belongs to the school-wide public courses that Each profession must have to learn. These courses are designed to training students with good political ideological quality, scientific literacy, constitutional health and instrument technical ability, these courses were equipped them with the foundation and capacity to further study professional knowledge of medical and improve the comprehensive quality, they are only the liberal education.

Professional elementary courses has both common character and pertinence, but for the medical professional categories, the major basic course mainly are the same, just has the difference requirements of the degree of certain courses for the different professional direction. The height of this commonality curriculum oriented provides good conditions for the establishment of the broad, thick foundation platform. We should take full advantage of this feature, in accordance with the requirements of "thick foundation, wide caliber, high quality" targets, adjusting, recombinating, and optimize the way of curriculum system. Breaking the barrier between the cross discipline, and strengthen, penetration and fusion the interaction between knowledge, reflect the new knowledge, new technology, make the highly systematic knowledge system, broaden the coverage and enhance the cross fusion degree to establish a solid foundation, broad education 
platform to support the professional training,culturing students with broad, solid basic knowledge and ability,lay firm foundation for their subsequent multi-direction and high-quality education.

2) Innovate the professional education and broaden the orientation of talents cultivation

The fundamental task of professional education is the cultivation of professional theory and professional skills. According to the target and requirements of cultivating talents in medical colleges and universities in the western mountain areas, professional education should give the student a solid professional theory and strong professional skills, and broaden the professional direction. Starting from this target, major courses and teaching contents should be both systematicness and pertinency, in another word ,it should put the reform of large professional courses in the first place, and integration of curriculum content of each professional major,or the common requirements, composed of large class of deep module with systematization, hierarchy, such as diagnosis, forensic surgery, internal medicine and department of surgery, gynecology and department of pediatrics ,the specialty course modules can be composed of these medical specialties, cultivating students' solid basic medical professional knowledge and skills. At the same time, we can establish a group of small class of professional courses that dynamic development change, face different professional directions, to meet the needs of professional education for later professional division, to cultivate the students' professional knowledge and skills in a direction professional emphasis. Then build a large class of course as the center,and small courses as peripheral, set the intercommunity and difference as one of professional education system, these methods can not only cultivate students' scientific ability, solid professional knowledge and skills, but also provide a broad space for the further development and enhance the direction of their choice.

3) Strengthen internship and practical training, fostering students with practical application ability and elevating their Innovation potential

The content of the course must be embodied in the training aim, highlight application, a strengthening comprehensive, and the pursuit of innovation; At the same time, we should paying attention to the interdisciplinary cross, fusion, or strengthen the course level,inter module connection(such as the correlation between basis and basis or between basis and clinical), It's necessary for optimizing and integration some teaching contents scientific to reduce the verification experiment and increase the comprehensive and design experiment,enhance the bedside teaching, reference cases in teaching, and give students much more chance to design and do it by themselives, cultivation of their comprehensive analysis ability ,practice ability and innovation thought as much as possible.In addition, We should use the existing conditions or try to create conditions to plan arrangements for some students to participate in the teachers' scientific research work, consciously cultivate the part of the students'scientific research ability and innovation ability. These practice teaching system, goes from the most basic level, to ensure the overall objectives of training in the "practical ability" culture, and goes from the high level,it's making some excellent students to steel themself in research ability, exercising innovation ability, creating conditions for them to become high quality and top-notch talents.

4) Increase the optional course and enhance Students' humanistic quality

The main function of selective curriculum is to broaden students' scope of knowledge, develops their individuality and improve their comprehensive quality. medicine university in western mountains areas is comparatively lack of the instructional resources of selective curriculum and with weaker teacher ship. Therefore, we must use of the existing conditions or create conditions to set up selective curriculum that obligatory, emphasize and reflect the characteristics as far as possible. According to the characteristics of higher medical education talent cultivation target in western mountainous areas, the instructional objectives setting of elective course should be around the following three aspects:

a) Curriculum mainly out of Pervasiveness and practicability

First, as a complement of compulsory curriculum, the optional course should give full expression to the require of mainstream direction of talent training, which means the course become more specificated and practical. And give priority to with universal, practical courses, farthest expand the student's scope of knowledge and made the students' personality development in many aspects, heighten their self-study ability and application ability. Only in this method can they adapt to the Multi-level and various people and the environment, then play its role to its full potential.

b) Set up basic educational curriculum protrude the humanities

The second, we must column the humanities science curriculum for emphasis of the optional course. Emphasize strengthening students' humanistic quality education. Therefore, increase the optional course will become an important measure for strengthening humanistic quality education. We should make full use of the conditions in our school or adopt measures to joint, introduction teaching resources, etc. to set up a series of humanities electives, especially outstanding the humanities foundation educational curriculum, mainly include literature, the history and philosophy to cultivate students the basic knowledge of humanities. On this basis, they can constantly enrich and expand their cultural knowledge level and accumulation, enhance their humanistic spirit through learning of other courses and various forms of comprehension and inspiration, sequentially to improve their humanistic quality.

c) Setting elective curriculum with perspectiveness, Futurity and expansibility

Third, proceed from the objective of chalk up high quality and high level talents in personnel cultivation, offer appropriate elective curriculum that reflects frontier discipline, interdisciplinary subject and High tech knowledge, the curriculum like biotechnology and biomedicine can not only expand students vision and improve the knowledge level of them, but also can lay the 
foundation for their further improve of the quality and release their potential abilities.

\section{Select the appropriate training methods}

The training method is in the first place, According to the characters of the practice teaching mainly for training the students capacity of practical professionals at the grass-roots level and the specific circumstance of poor teaching conditions in western mountainous areas, we should still attaches great importance to the students' knowledge learning and excavate the advantages of traditional teaching method actively, innovate the training methods with dauntless and focus on actual effect to cultivate students with solid basic knowledge of medicine. Simultaneously, sparkplug and quote heuristic method and problematic progressive teaching method energetically, training students with nice ability of comprehensive analysis of problems, solve problems and ability of creative thinking.

The teaching means ranked the second, currently a new teaching means that popular in the western mountains is the multimedia teaching, which flourishes everywhere and dominant party. While the indication of multimedia instruction increasingly apparent and seriously affect the teaching quality. Consequently, we should have a correct understanding to the reform of teaching means, we should clear and definite that the teaching method merely a kind of pattern, and then the reform is based on the content -and a teaching method based,it would be a scientific and efficient innovation.

Then pay attention to the teaching mode,the teaching mode mainly include educational system, curriculum mode, the shunt and cut-through,the medicine institutions in western mountainous area should select appropriate teaching mode according to its own conditions and characters, or the talent cultivation requirements.actively explore a flexible educational system,such as a program with the characteristics of the credit system, continuous reform, improve the implementation of the current mode of convergence at the first stage and shunt later. on the other hand,Qualified college can try "Bachelor and master through training mode", culture diversification, multi standard, multi level medical talents.

\section{Construct a favorable education environment}

The educational environment is a place for educating, Specifically, College education environment is the environment of University Campus, which include dominant situations such as buildings in the schoolyard, landscape, distribution, Lebensordnung, the visualize of staff and students and recessive environment like civilization and academic atmosphere in the campus. All of these environment factors plays an important role in the quality of talent cultivation.

\section{REFERENCE}

[1] Wen DL, Chen JB, Liu Q, Yang X, Ji XF, Wang GJ. Study on make full use of modern educational technology for the systematic training mode of primary care physicians. China Medical Education Technology. 2013 27(3).

[2] Zhou Y, Mou KH, Han D, Wang GJ, LShemin . Survey of the current status of continuing medical education in a primary-care hospital of Shaanxi Province and countermeasures. China Medical Education Technology. 2015(4):1027-32.

[3] Deng HF, Ma YX, Yao F, Luo S, Zuo Q, Zhou Q, Li J, Tan YL Chen XL. The model of pathological physiology autonomous learning based on campus network. China Medical Education Technology. 2015(1):536-9.

[4] Wang GQ, Tang J, Hao J. Analysis of Medical Teachers' Humanities Quality. Northwest Medical Education. 2012 20(5):338-40.

[5] Xiang Q, Li Q, Zhang J, Huang J, Guo Y, Sun HBs. Discussion on the Medical Professionalism. Northwest Medical Education. 2013 21(6).

[6] Wang X, Hou Y, Deng K, Zhang Y, Wang DC, Ding J. Structural insights into the molecular recognition between cerebral cavernous malformation 2 and mitogen-activated protein kinase kinase kinase 3. Structure. 2015, June 2; 23:1-10

[7] Wang X, Ding J*and Wang DC*, Crystallization and preliminary $\mathrm{X}$-ray analysis of the $\mathrm{C}$-terminal domain of CCM2, part of a novel adaptor protein involved in cerebral cavernous malformations, Acta Crystallo- graphica Section F, Jun 1;68(Pt 6):683-6, 2012

[8] Xu X, Wang X, Zhang Y, Wang DC*, Ding J*, Structural Basis for the Unique Heterodimeric Assembly between Cerebral Cavernous Malformation 3 and Germinal Center Kinase III, Structure, Jun 4;21(6): 1059-66, 2013

[9] Xu X, Wang X, Ding $\mathrm{J}^{*}$ and Wang DC*, Crystallization and preliminary crystallographic studies of CCM3 in complex with MST4 C-terminal domain. Acta Crystallographica Section F, Jul 1;68(Pt 7):760-3, 2012

[10] Ding J, Wang X, Li DF, Hu Y, Zhang Y and Wang DC*, Crystal structure of human programmed cell death 10 complexed with inositol- $(1,3,4,5)$-tetrakisphosphate: a novel adaptor protein involved in human cerebral cavernous malformation, Biochem. Biophys. Res, Commun. 399, 587-592.2010. 